\title{
Evolutionary Economics celebrates Innovation and Creativity based Economy
}

\author{
Hokky Situngkir \\ [hs@compsoc.bandungfe.net] \\ Dept. Computational Sociology \\ Bandung Fe Institute
}

\begin{abstract}
The paper draws issue on the evolutionary economics that open our mind on seeing economy as growing and living organism with any characters of robustness, self-organization, adaptation, and evolution. This has been recognized, as in global picture, we enter the phase in which information and knowledge acquisition rapidly plays a major role in economy. The discussions is presented by demonstrating some qualitative properties and theoretical explorations on long range historical economic growth and development and thus followed by some highlights on innovation, creativity and elaborations regarding to fitness landscapes incorporating memetics, as works related to social and cultural aspects of social system, while talking about economic system in general. The discussions depicts some important notions on market and product diversifications that have been the source of the economic growth in general.
\end{abstract}

Keywords: evolutionary economics, global economy, creativity, innovation, diversification, memetics. 


\section{Introduction}

Recent economic discussions are rainbow of thoughts related to aspects that conventionally and traditionally do not related directly to economics itself, for instance issue on happiness (Johns \& Ormerod, 2007), creativity and technology (Towse, 2001), and a lot more issue that seemingly reveals the fact the high complexity of economy and interdisciplinary might be the solution to problems aroused. Some interdisciplinary works are shown though by the emerging of econophysics (Roehner, 2002), evolutionary thoughts on economics as compiled by Foster \& Hözl (2004), and even finance (Dowling, 2005). These are trends in economics, seeing economy as a growing and living organism with any characters of robustness, self-organization, adaptation, and evolution.

While the heart of economic growth and improvement is innovation, creativity, information and knowledge acquisitions towards the economic processes, the development of information technology, being part of the development of global economy, has brought us a lot of ideas on the evolution, growth, and cycles in the economy. This is the task that would like to be delivered and demonstrated by the paper. It is more like broaden the economic discussions into the economy with all of its social aspects (be it cultural, political, legal, and all related aspects) in notions and our recent understanding on inductive inference of the emergence of creativity (be it in the microscopic or macroscopic level of society) along with the notions of evolutionary search and adaptability of social living.

The discussions of the paper begin with some symptomatic approach to the brief outline of the historical global economy. This interesting discussions on fascinating recent phenomena in our economy then follows the discussions about the role of innovation and creativity while we observe economic system. Both then be discussed by including some facts of growing creative industry and general economy. The paper ends by concluding some important aspects related to the fitness landscape of economic development, diversification, globalizations, and further conjectures that could celebrates what proposed by the paper is.

\section{Evolutionary Landscape: A Brief History of Global Economy}

The recent growing and global economy has emerged to the importance of the role of information to be put into account - even further, some certain information has now intrinsically has economic value. While the symmetry of information has been an important issue in economics and discussed since long, the growing economy has now included the internet and rapid telecommunication devices into its process (be it production, distribution, and consumption of goods and products). The latest have grown the economy which some particular information have high economic values, be it supportive to the economic processes or even become, let alone, a product itself.

\begin{tabular}{|c|c|c|c|}
\hline $\begin{array}{c}\text { Manufacturing } \\
\text { Centered } \\
\text { Economy }\end{array}$ & $\longrightarrow$ & $\begin{array}{c}\text { Hi-Tech } \\
\text { Economy }\end{array}$ \\
\hline Industry & $\begin{array}{c}\text { Electronics over } \\
\text { Industry }\end{array}$ & $\begin{array}{c}\text { Creativity and } \\
\text { Innovation-Based } \\
\text { Economy }\end{array}$ \\
\hline $\begin{array}{c}\text { Innovation over } \\
\text { industry }\end{array}$ \\
\hline
\end{tabular}

Figure 1. The historical evolutionary plot. 
Reading the history of global economy has tempted us to accept qualitatively the exposition of the growing economy in to steps of evolution from the manufacturing-centered economy, high technology based economy, and the coming creative and innovative economy. This is shown in figure 1.

The most stunning and interesting collaboration between science and technology with social living is the western industrial revolution in the eighteenth century. The revolution was introduced by the massive industrial establishments originated by the introduction of John Smeaton and James Watt's innovation on Newcomen steam engine (McClellan III \& Dorn, 2006: 279). This innovation changed the economy as the value-addition processes become more massive, efficiency-pursuer, as well as, manufacturing centered endeavors. The high technology especially the high speed economic system as powered by the rapidly growing computer, electronics, and instruments (as well as transportation) technology has acknowledged to be a new pattern that can be recognized as the second industrial revolution (James, 2000). This is marked since the times of huge direct investment in European factories after the Marshall Plan in 1952. Those technology output, i.e.: computer, electronics, and instruments are massively incorporated to pursue the efficiency of the production and distribution processes. This is the era of the Hi-Tech economy.

Nonetheless, as favored by a lot of futurists, Moore's Law (Moore, 1965) has changed we employ electronics in our lives. The exponentially increasing electronic components in integrated circuit - the most important part in modern electronic devices - is related to the general capabilities of digital electronics, e.g.: processing speed, memory capacity, even the resolution of digital cameras. In this epoch, the computer, electronics, and instruments are produced as consumer products. Here, the content of the information technology becomes very important roles, be it as products but also as the supportive wares for marketed consumer technological products.

Innovation thus cannot be reduced into the processes of boost up efficiency but also into the achievement for best customer-friendly (read: user-friendly) for sophistication of information technology is a thing that matters. As noted by Schumpeter (1939), the innovation is the source of any recognized long term business cycles. Innovation is related to the incorporation of novelties of knowledge in economy. As formalized by Aghion \& Howitt (1992), innovation is demonstrated - as pointed out descriptively by Schumpeter - as the creative destruction, in which entrepreneurial innovation destroys the value of existing physical and human capital in order to emerging the new value of the new ones. While this knowledge-related aspect of economy is thence related to the knowledgebased economic products in the age of (high-tech) information-based (technological) economy, the growing (and emerged) economic and business cycles become more interesting. Discussions about the production process in the sense of learning, i.e.: learning by doing (Auerswald, et. al., 2000), shows how the concept of learning becomes important to see the long-term evolutionary economic process.

New (innovated) products are not necessarily to destroy the market of the older one but can also be seen as a kind of diversification of products. Diversification of products is standing side by side with the discourses of innovation in general economic processes. Diversification can be regarded as respect to products as well as market. Product diversification is a variable related to innovation and creativity appearing the artifacts for the consumers while market diversification is related to the way of marketing target of the particular products. The latest has been related to the advertising techniques and any other endeavors for catching the consumer's appeal.

Another interesting aspect of the incoming creativity-based industry is that it relates on how the information-based products and technologies interacting with the user since it affects culture as 
portrayed by a lot of postmodernist thinkers (e.g.: cf. Kellner, 1995). The industrial gap between the developed and under-developed countries in the high tech economy has let such kind of deterritorialization for the possibility of very-rapid communication and the information traffic from one place to another place (Tomlinson, 1999). Globalization is the face of the emerging world culture. Critical thinking has aroused suspecting global economic order which in turn yield the globalization as a sort of homogenization of the world culture (Hannerz, 1991). This is related to daily cultural artifacts, e.g.: music, fashion and lifestyles.

\section{Modeling the Innovation in Economic Evolutionary Processes}

As we have discussed previously, having an abstraction of innovation in evolution of economic system can be regarded as a challenge of speaking about creativity but not in the sense of the induction of an idea in human mind, individually the first one is in the social landscape and space. This is since both creativity, induction (micro-social, individual) as well as innovation (macro-social, collective individuals) can be seen as the problem of a sequence of symbols emitted by an unknown stochastic source. In the other hand, the discussions of evolutionary perspectives can roughly be recognized as a heuristic search for optimality, be it global or local optima (Gen \& Cheng, 1997). This has also inspired the incorporation of the concept of meme as a smallest unit of information (Dawkins, 1975) to the computational sociology of cultural evolution (Situngkir, 2004).

The perspective of evolution to the innovation would urge us to assume the existence of a landscape reflecting the features of economic products in which the fitness of each product would be ruled by the market or the quantities of the adoption of the products by consumers. Kauffman et. al. (2000) exemplified this by demonstrating the model of technology landscape based on the evolutionary NKLandscape model. Since the concept of memeplex - the sequence of memes - reflects the features of cognitive recognition on products, we could built a face of the evolutionary economics in simple way. The idea of the evolution and innovation here is thus modeled as the heuristic search in a landscape, and creativity thence is regarded as finding higher fitness by the space of memeplexes.

Let us denote a search space $S^{t}$ and a function

$$
f: S^{t} \rightarrow \Re
$$

thus the general evolutionary process is to find

$$
a^{*}(t)=\max _{a \in S^{t}} f
$$

where

$a \quad$ : vector of memeplex reflecting the mental representation of artifacts

$f \quad$ : the objective function, mapping the corresponding artifacts or objects to the fitness value

$a^{*}(t)$ : global optimum at certain time $t$, a vector which is the "fittest" among other available sequences at time $t \in T$.

The variations among artifacts are measured by using the Hamming distances which counts the number if the positions where two sequences differ, mathematically written as, 
$d: S^{t} \times S^{t} \rightarrow \mathfrak{R}^{+} \cup\{\infty\}$

for which is required that

$d(x, y) \geq 0$

$d(x, y)=0 \Leftrightarrow x=y$;

$d(x, z) \leq d(x, y)+d(y, z)$

$\forall x, y, z \in S^{t}$

thus the symmetric distance measure is fulfilled,

$d(x, y)=d(y, x), \forall x, y \in S^{t}$

Here, the distance between artifacts defines the metric system on the evolutionary changing system on $S^{t}$.

Moreover, the metaphor of fitness landscape $L^{t}$ can be written as a function of $L^{t}=\left(S^{t}, f, d\right)$ containing both the local and global optimal. In particular case, a vector $x \in S^{t}$ is recognized to be local optimum if $f(x)>f(y)$, while there exists $f(z)>f(x), \forall x, y, z \in S^{t}$.

As it has been discussed, some particular modeling techniques are incorporating the binary models, thus the fitness function can easily written as

$f(a)=\frac{1}{N^{t}} \sum_{i=1}^{N^{t}} f_{i}\left(a_{i} ; a_{i 1}, a_{i 2}, \ldots, a_{i k}\right)$

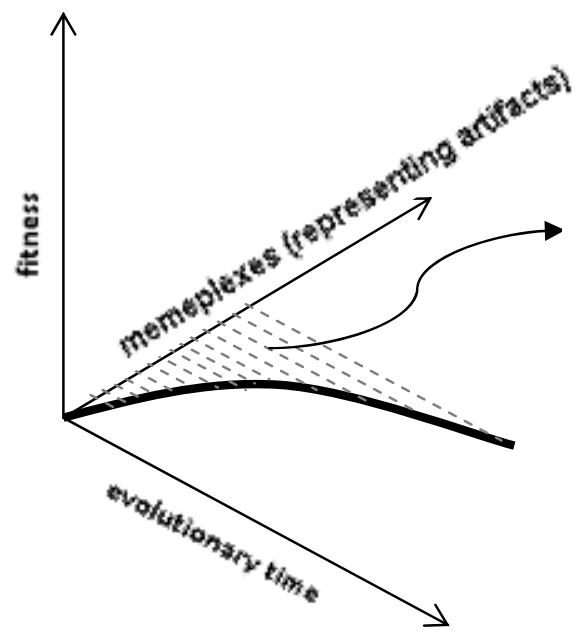

Figure 2. The Representation of Memetic Fitness Landscape 
Where $k \in K$ represents the epistatic states between memes. The representation of memetic fitness landscape thus can be drawn in the three dimensional Cartessian coordinate system as shown in figure 2. While the fitness is ruled by the meeting of the supply and demand in the market or in simpler phrase, the adoption of certain artifacts, the memeplex is governed by evolutionary search for the new innovation, be it creativity in the additional and small features within older memetic sequences or a more extreme changes. Some scholars named both changes as incremental and radical innovation respectively (Ettlie, et. al., 1984). Through the landscapes, the innovation is thus "wandering" over time and over memeplexes to have the higher fitness.

Thus, from figure 2, we can see that the innovation is the matter of enlargement of the included variations of memeplexes, while fitness depends upon the consumer adaptability to certain changes over products/artifacts. The stochasticity of the innovation lies upon the coming of new variations over the existing diversity. New additions to the landscape of the memeplexes-evolutionary time is what we denote as novelty. Good novelty is one with good acceptance by the environment of it. While the object we modeled is a product, the fitness is then the market in which it is marketed. This, apparently, does not close the possibility that the object is a kind of policy chosen macroeconomically, for instance, and the social system Here we can show the importance of the diversity while we are talking about evolutionary process (cf. Curran, et. al., 2007). The urgency and need for diversity comes while we observe the processes of production while homogenization is frequently felt while only some artifacts/products reach the point of optimality in the market.

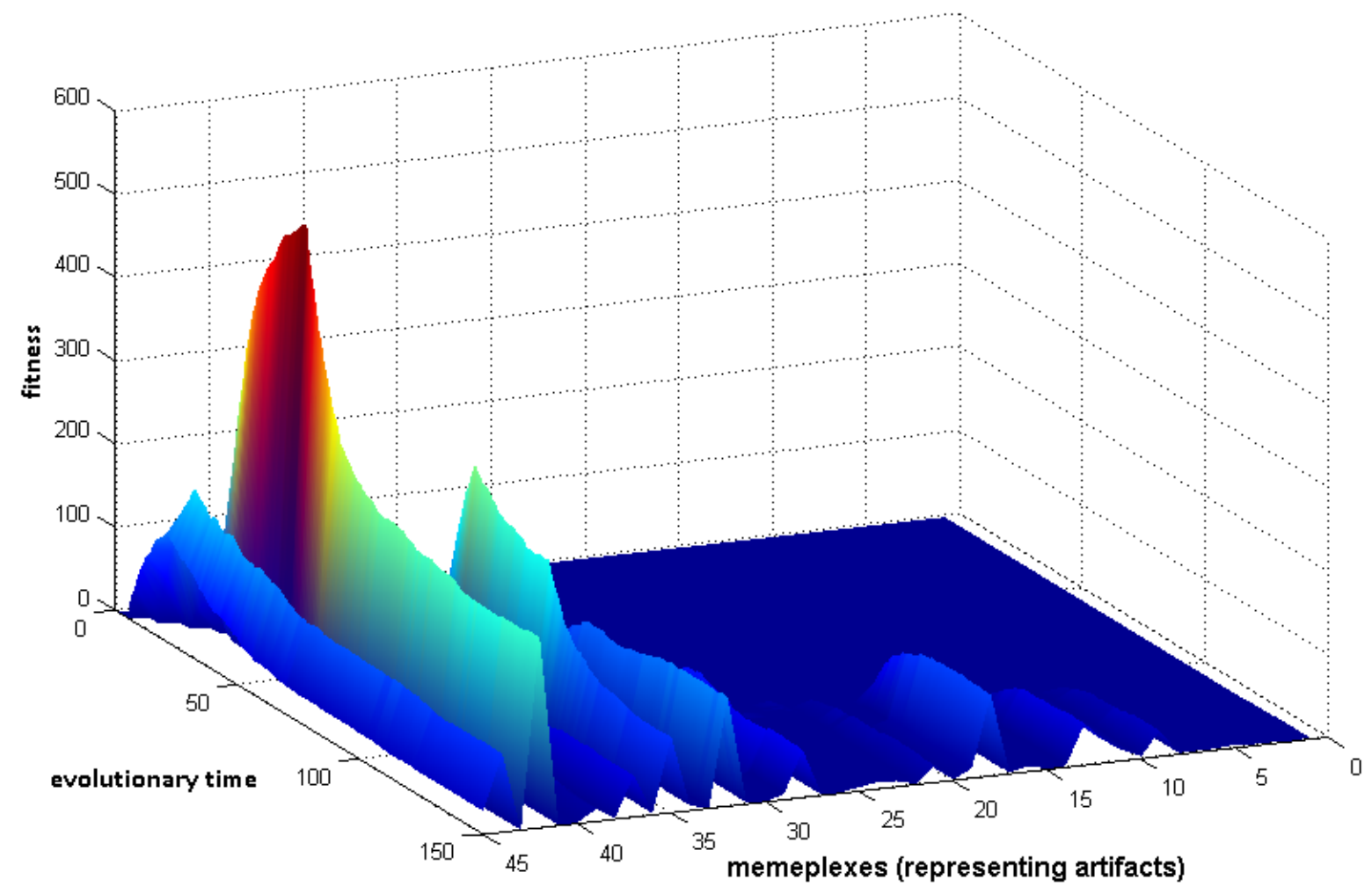

Figure 3. Simulated Memetic Fitness Landscape (Data: Khanafiah \& Situngkir, 2006) 
Using the above model and incorporating the data yielded in the simulation as presented in Khanafiah \& Situngkir (2006), we draw the evolutionary landscape as presented in figure 3. We do the simulation using the diverse possible artifacts represented by randomly generated binary memeplexes. The iterations of the computer simulations are made up from epochs of which some rounds. Differing the dynamical modeling with evolutionary one, we can say that each epoch represent the evolutionary changes while the rounds of iteration the dynamics of the circumstances.

Figure 3 presents the landscape yielded from computational simulation. It is obvious that as time grows the diversity or possibility in the landscape grows. Any newly introduced objects would change other's acceptance and presenting new faces of the landscape. Apparently this kind of landscape would be revealed on any long term economic system, yet, the information and knowledge based products as we have seen in to day economic trend make the faster evolutionary epoch. The innovation does not have to related directly to the core products. For example, the way of bottling particular kinds of beverage could have change the acceptance of the market, and this lies under the uncertainty of the market. A policy in a place to overcome a problem in particular community does not have to be applicable to other places with the similar problem. The epistatic among meme in the memeplex sequences could come from the endogenously (within the products) and exogenously (market, society).

\section{Discussions}

As the market of information, content, and knowledge based products are opened everywhere from now and then, we have abundant information flowing through our glass-screen of television, LCD's laptop or even phone handset. The rapid information market has made our perspective on creativity in the market clearer.

Table 1

The Simple Three Epochs in Our Global Evolutionary Economic System

\begin{tabular}{|c|c|c|c|}
\hline & $\begin{array}{c}\text { Manufacturing Center } \\
\text { Economy }\end{array}$ & High Tech Economy & Creative Economy \\
\hline Product Quantities & Scarce & Medium & Abundance \\
\hline $\begin{array}{c}\text { Information } \\
\text { Quantities }\end{array}$ & Scarce & $\begin{array}{c}\text { Medium, localized in academic } \\
\text { environment }\end{array}$ & Abundance \\
\hline $\begin{array}{c}\text { Asymmetry to be } \\
\text { Equilibrate }\end{array}$ & Political access & Technology access & Information \\
\hline Landscapes & Nations (geopolitics) & Spaces (borderless) & Digital \\
\hline
\end{tabular}

Considering the new economic trend, the changes have information is to be classified now in categories: whether an info is a message for bulk or really important. Here, a lot of persons have hypothesized the new kind of economy. An information, in which has economic value or not, the heart of this new economy. This is an era of creative economy; an economy in which innovation is the most important. No matter how bad our product, the important is laid upon the innovation came together with the product. Diversity and heterogeneity of products is laid upon features in which a product has. Mainly related to 
information and knowledge management issue, we can elaborate the table 1 presenting the three phases of the evolution of economy as previously shown in figure 1.

The tendency to enrich the global landscape is very important similarly with the endeavor to enlarge the market in which adoption of particular products higher. In the earlier section we have discussed about the need of market along with product diversification in the newly economy ruled by the novelties and creativity. A reflection of the both is presented for several countries in figure 4 . There is shown how China enjoyed the highest export volumes for arts and crafts which are commonly regarded as the most important in the creative industries. From the datasets, France cherish the highest product diversification which, roughly speaking, diversify products most successful with a lot of interesting innovations. This is contrary with what we found in Indonesia, which recognized to be one of the countries with highest diversities in ethnicities which consequently holding enormous sources of creativity. Indonesia holds country with the highest market diversification but yet, relatively low diversification on products. The innovation for diversification of products from the large sources of diversification i.e.: local geniuses with various and wide aspects of product diversification seemed to fail while the marketing has greatly recognized. This is an important evaluation related to strengthening economy for we know that countries like China which slightly higher product diversification and relatively low market diversification enjoy such great export toll. A slight visionary policies to Indonesian product diversification would have boosted up the income for the people of the countries.

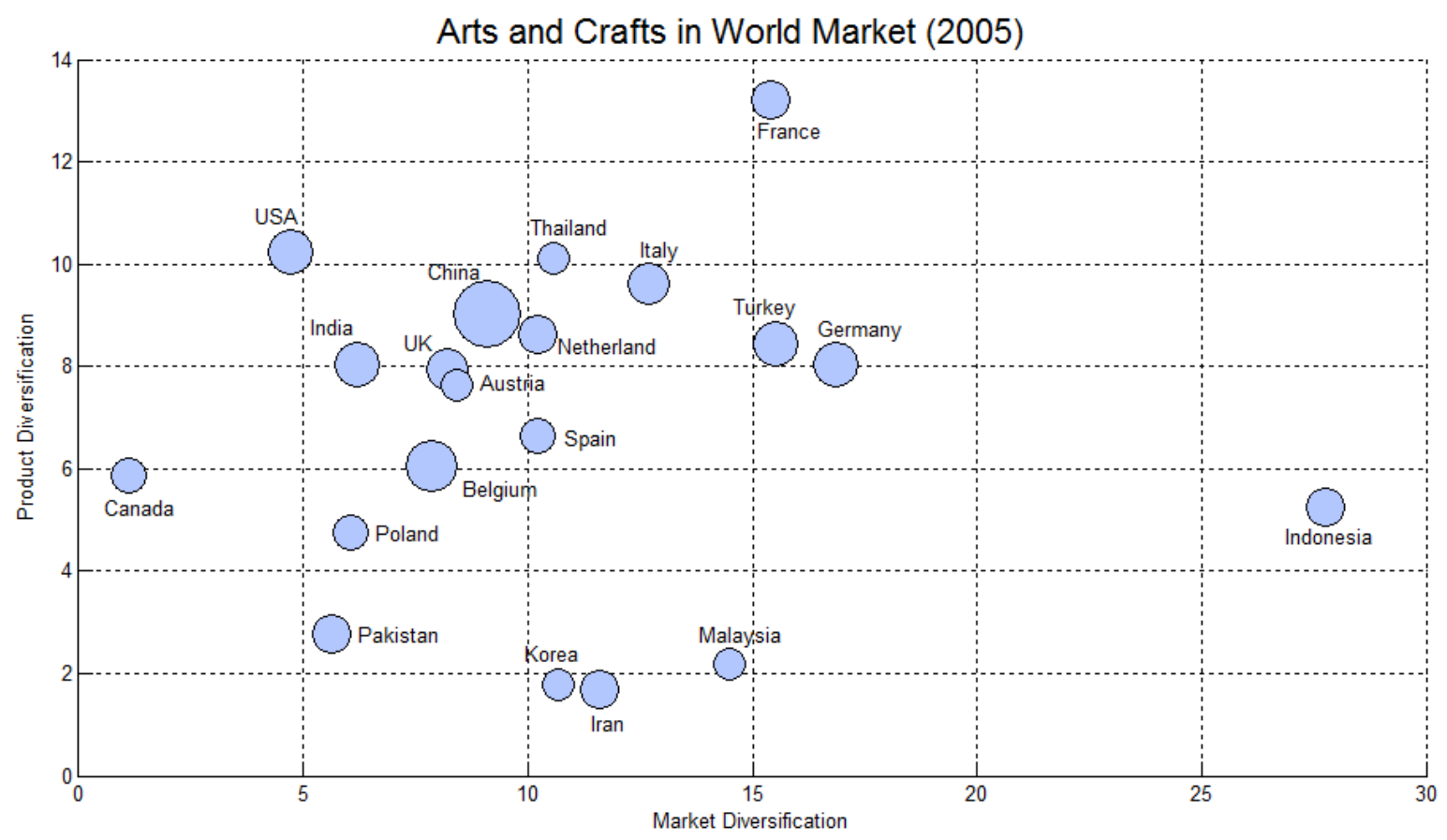

Figure 4. Market and Product Diversification of Craft and Arts in World Markets with size of the bubbles proportional to total country exports (Data: UN, 2008)

Interestingly, creative economy is not merely about arts and crafts. The consequence of our understanding that general economic creativity and innovation is by means of preparing and the never ending processes of searching for alternatives, is that in order to gain in the economic processes one 
should open larger and larger scope of viewpoints regarding respectively. Policies are actually can be seen as a kind of economic objects, and the enlargement of perspectives related to the possible in micro and macroeconomic policies become obviously relevant. This is not to say that the evolutionary concepts can also bring explanation on why economic policies are not that easily applied from places to places even though seemingly in the need to overcome similar problems. This is somewhat related to the notion of path dependency and the fact about increasing return in a lot of economic phenomena (Buendia, 2005). A lot of standard and conventional economic rule of thumb has been needed this understanding when it comes to policy-making - this is a fact without forgetting some important notions related to incorrect assumptions where modern economics laid upon (cf. Keen, 2002).

Thus, the grasp of larger viewpoints and diversities are important in the sense of economic policies in wide range description level of economy. Just like in the discussions related to inductive inference, the evolutionary economics makes point of enlargement of horizon, embracing surprises and novelties in the wide scale of observation.

\section{Concluding Remarks}

We have discussed the trends in global economy in evolutionary perspective, be it qualitatively speaking related to the symptomatic aspects followed by the proposed modeling of computable evolutionary models on human culture, memetics. From the symptomatic overview, we could see that the recent global economy has been celebrating the very different economy governed by the acquisition of knowledge and information supported by the related technological growth and developments. The intensive and rapid grow of electronics, computer, telecommunication, and transportation technology has emerged the creativity based economy turns out some continuums in social aspects. First, it influences the way of production and distribution of goods that is thirsty for diversifications. Second, it affects the emergent social behavior geographically for the high traffic of information including cultural objects crossing geopolitical and geo-ethnical borders, in short the consumer behavior on goods.

From the computational and formal standpoint, we could apparently observe the role of "diversification" and understanding about "epistatism" in some aspects of economy in general. Economy should not be seen as a merely dynamical processes or even worse as static. Economy is an open system which large variations of point of view should be put into account be it to produce in the microeconomic level of firms and industry and even larger macroeconomic horizon. The search for alternatives is even important to open the coming and applications of which novelties and creative including critical. Qualitatively speaking, the uncertainty in economy is somehow come from such limited horizon of our perspectives as economic agent. This is has been shown apparently in the formulation of the metaphorical fitness landscape of economic development.

Our further discussions have also brought us to the reflection on empirical facts about market and product diversification on several countries in global economy related to the national arts and crafts. France is recorded as country with highest diversification of the products even though it is China who celebrates the highest export value on this sector. Both countries cherish the diverse society as Indonesia respect to traditional heritages as a good sources crafts and arts, however, the diversification of the products is felt to be low still. It is worth noting that this discussion obviously not limited the creative economy into merely on arts and crafts as the wide commonsensical thought it to be. 
Overall, it promises a great excitement and fun to see how the evolutionary market governed by limitless creativity and innovations is enabling us to give us an evolutionary understanding of the market in general.

\section{Acknowledgement}

I thank friends in Indonesia Archipelago Culture Initiatives for research-related discussions about this issue and Surya Research International for support in which period the paper is written.

\section{References}

Aghion, P. and Howitt, P. (1992). "A Model of Growth Through Creative Destruction". Econometrica 60 (2). Cambridge. MIT Press.

Auerswald, P., Kauffman, S., Lobo, J., \& Shell, K. (2000). "The Production Recipes Approach to Modeling Technological Innovation: An Application to Learning by Doing". Journal of Economic Dynamics and Control 24.

Buendia, F. (2005). "Business Competition as a Self-organizing Process: Toward an Increasing Returns-Based Microeconomic Theory". In Salzano, M. \& Colander, D. (eds.) New Economic Windows. Springer.

Curran, D., O'Riordan, C., \& Sorensen, H. (2007). "Evolving Cultural Learning Parameters in an NK Fitness Landscape". In Almeida e Costa, F. (ed.) Advances in Artificial Life. Springer-Verlag.

Dawkins R. (1976, 1982). The selfish gene. Oxford UP.

De Long, J. B. 2000. "The triumph of monetarism?". Journal of Economic Perspectives 14 (1).

Dimand, R. W. (2003). "Interwar Monetary and Business Cycle Theory: Macroeconomics before Keynes". In Samuels, W. J., Biddle, J. E., Davis, J. B. (eds). A Companion to the History of Economic Thought. Blackwell.

Dowling, B. F. (2005). Evolutionary Finance. Palgrave.

Ettlie, J. E., Bridges, W. P., O'Keefe, R. D. (1984). "Organization Strategy and Structural Differences for Radical Versus Incremental Innovation". Management Science 30 (6).

Foster, J. \& Hözl, W. (2004). Applied Evolutionary Economics and Complex Systems. Edward Elgar.

Gen, M. \& Cheng, R (1997). Genetic Algorithms \& Engineering Design. Wiley Publication.

Hannerz, U. (1991). "Scenarios for Peripheral Cultures". In A. King (ed.). Culture, Globalization and the WorldSystem. Binghamton. State University of New York.

James, H. (2000). "The Fall and Rise of the European Economy in the Twentieth Century". in Blanning, T. C. W. (eds.). The Oxford History of Modern Europe. Oxford UP. pp. 186-213.

Johns, H. \& Ormerod, P. (2007). Happiness, Economics, \& Public Policy. The Institute of Economic Affairs.

Kauffman, S., Lobo, J. \& Macready, W. G. (2000). "Optimal Search on a Technology Landscape". Journal of Economic Behavior \& Organization 43.

Keen, S. (2002). Debunking Economics: The Naked Emperor of the Social Sciences. Pluto Press. 
Kellner, D. (1995). Media Culture: Cultural Studies, Identity, and Politics Between the Modern and the Postmodern. Routledge.

Khanafiah, D. \& Situngkir, H. (2006). Innovation as Evolution. Paper presented in the $5^{\text {th }}$ Computation and Intelligence in Economics and Finance Conference, Kaoh-Siung, Taiwan 2006.

McClellan III, J. E. \& Dorn, H. (2006). Science and Technology in World History: An Introduction 2nd ed. John Hopkins UP.

Moore, G. E. (1965). "Cramming more components onto integrated circuits". Electronics Magazine 4.

URL: ftp: //download.intel.com/museum/Moores_Law/Articles-

Press_Releases/Gordon_Moore_1965_Article.pdf

Reeves, C. R. (1999). "Fitness Landscapes and Evolutionary Algorithms". Selected Papers from the 4th European Conference on Artificial Evolution. Lecture Notes In Computer Science 1829. Springer-Verlag.

Roehner, B. M. (2002). Patterns of Speculation: A Study in Observational Econophysics. Cambridge UP.

Schumpeter, J. A. (1939). Business Cycles, 2 vols. New York: McGraw-Hill.

Situngkir, H. (2004). On Selfish Memes: Culture as Complex Adaptive System. Journal of Social Complexity 2(1).

Solé, R. V., Manrubia, S. C., Benton, M., Kauffman, S., Bak, P. (1999). “Criticality and Scaling in Evolutionary Ecology". Tree 14 (4).

Solomonoff, R. (1975). "Inductive Inference Theory - A Unified Approach to Problems in Pattern Recognition and Artificial Intelligence." Proceedings of the Fourth International Joint Conference on Artificial Intelligence, Tbilisi, Georgia, U.S.S.R. pp. 274-280. URL: http: //world.std.com/ rjs/tblisi 75 .pdf

Tomlinson, J. (1999). Globalization and Culture. Polity.

Towse, R. (2001). Creativity, Incentive and Reward: An Economic Analysis of Copyright and Culture in the Information Age. Edward Elgar.

The United Nations (UN). (2008). Creative Economy Report 2008. UNDP \& UNCTD. 